Author has nothing to disclose with regard to commercial support.

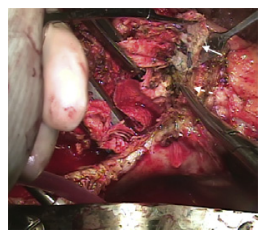

\section{IS BIOLOGIC GLUE THE INEXPERIENCED SURGEON'S BEST FRIEND?}

Reply to the Editor:

In their letter to the Editor, Lee and Choi ${ }^{1}$ reported their experience of 99 patients with acute type A aortic dissection (ATAAD) treated with BioGlue (CryoLife Inc, Kennesaw, Ga) and tetrafluoroethylene felt for the proximal reconstruction such that root replacement was necessary in only $7 \%$ of patients. In 9 years, only 1 patient required reoperation. Lee and $\mathrm{Choi}^{1}$ imply that because our group did not use biologic glue to preserve the aortic root we had to replace the aortic root more frequently. ${ }^{2}$ This Korean group's only criterion for aortic root replacement apparently is root diameter greater than $4.5 \mathrm{~cm}$, but Lee and $\mathrm{Choi}^{1}$ did not report their operative mortality, major complications, median follow-up time, late survival, or completeness of follow-up.

Our criteria for root replacement includes diameter of at least $4.5 \mathrm{~cm}$, known connective tissue disease, intimal tear in the aortic root, and irreparable aortic valve pathology. ${ }^{2,3}$ Otherwise, we repair the aortic root without any biologic glue or tetrafluoroethylene felt. ${ }^{2}$ To date, we have treated 138 patients in 7 years with this approach. Our 30-day and in-hospital mortalities are $5.8 \%$ and $6.5 \%$, respectively (Table 1). With $100 \%$ follow-up, $100 \%$ of our patients are free from proximal aortic aneurysm, anastomotic pseudoaneurysm, or any reoperations for proximal aortic pathology from the aortic root to the arch. One challenge that this Korean group may be facing-as they admit-is low ATAAD annual case volume (approximately 11 cases per year during 9 years) shared by many surgeons. As shown in the Duke experience, development of a dedicated thoracic aortic team (including a limited number of cardiovascular surgeons, cardiac anesthesiologists, perfusionists, and critical care specialists) dramatically improves outcomes for these patients. ${ }^{4}$ Perhaps more importantly, treatment of patients with thoracic aortic diseases, including ATAAD, must be regionalized, and whenever possible, patients with ATAAD should be transferred to centers with special expertise and large experience. ${ }^{5}$ Indeed, this is occurring in the United States. At the University of Michigan, we are currently treating approximately 60 patients with ATAAD a year with 3 focused aortic surgeons. Similarly, the Stanford group is treating 70 to 80 patients with ATAAD annually. Volume and experience do help.
TABLE 1. Perioperative outcomes

\begin{tabular}{lc}
\hline \multicolumn{1}{c}{ Variables } & All ATAAD $(\mathbf{n}=\mathbf{1 3 8})^{*}$ \\
\hline Reoperation for bleeding & $4(3 \%)$ \\
Myocardial infarction & $0(0 \%)$ \\
Cerebrovascular accident & $6(4 \%)$ \\
$\quad$ Permanent stroke & $1(0.7 \%)$ \\
Paraplegia & $1(0.7 \%)$ \\
New-onset renal failure & $10(7 \%)$ \\
$\quad$ with dialysis & $2(1.4 \%)$ \\
Long-term dialysis & $5(3.6 \%)$ \\
Sepsis & $4(3 \%)$ \\
Need for tracheostomy & $10(7-20)$ \\
Total length of stay (d) & $0(0 \%)$ \\
Intraoperative mortality & $8(5.8 \%)$ \\
30-d mortality & $9(6.5 \%)$ \\
\hline In-hospital mortality &
\end{tabular}

Data are presented as median and interquartile range for continuous data and $\mathrm{n}(\%)$ for categoric data. ATAAD, Acute type A aortic dissection. *Aortic root repair, $56 \%$ $(\mathrm{n}=78)$; root replacement (Bentall or David procedures), $35 \%(\mathrm{n}=48)$; aortic valve replacement, $1 \%(\mathrm{n}=2)$; no root procedure, $8 \%(\mathrm{n}=10)$.

Is biologic glue really safe? In addition to numerous publications discussed previously, ${ }^{2}$ in 2017 and 2018, 4 articles were published $^{6-9}$ on the use of biologic glue in ATAAD. Three articles described complications from biologic glue in aortic root repair ${ }^{7,9}$ or valve-sparing aortic root replacement. ${ }^{8}$ A single article $^{6}$ reported no adverse effects; this was the article cited by Lee and $\mathrm{Choi}^{1}$ to support their use of BioGlue. In that study, ${ }^{6}$ however, most of the patients had aortic aneurysms, and only 49

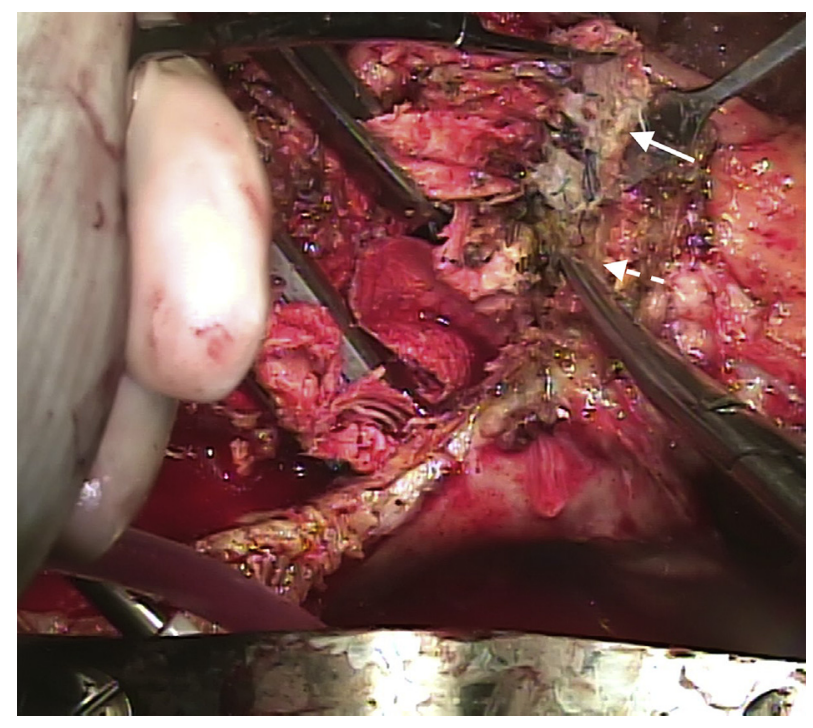

FIGURE 1. Adhesions and necrosis from biologic glue (dashed arrow) and polytetrafluoroethylene felt (solid arrow). 

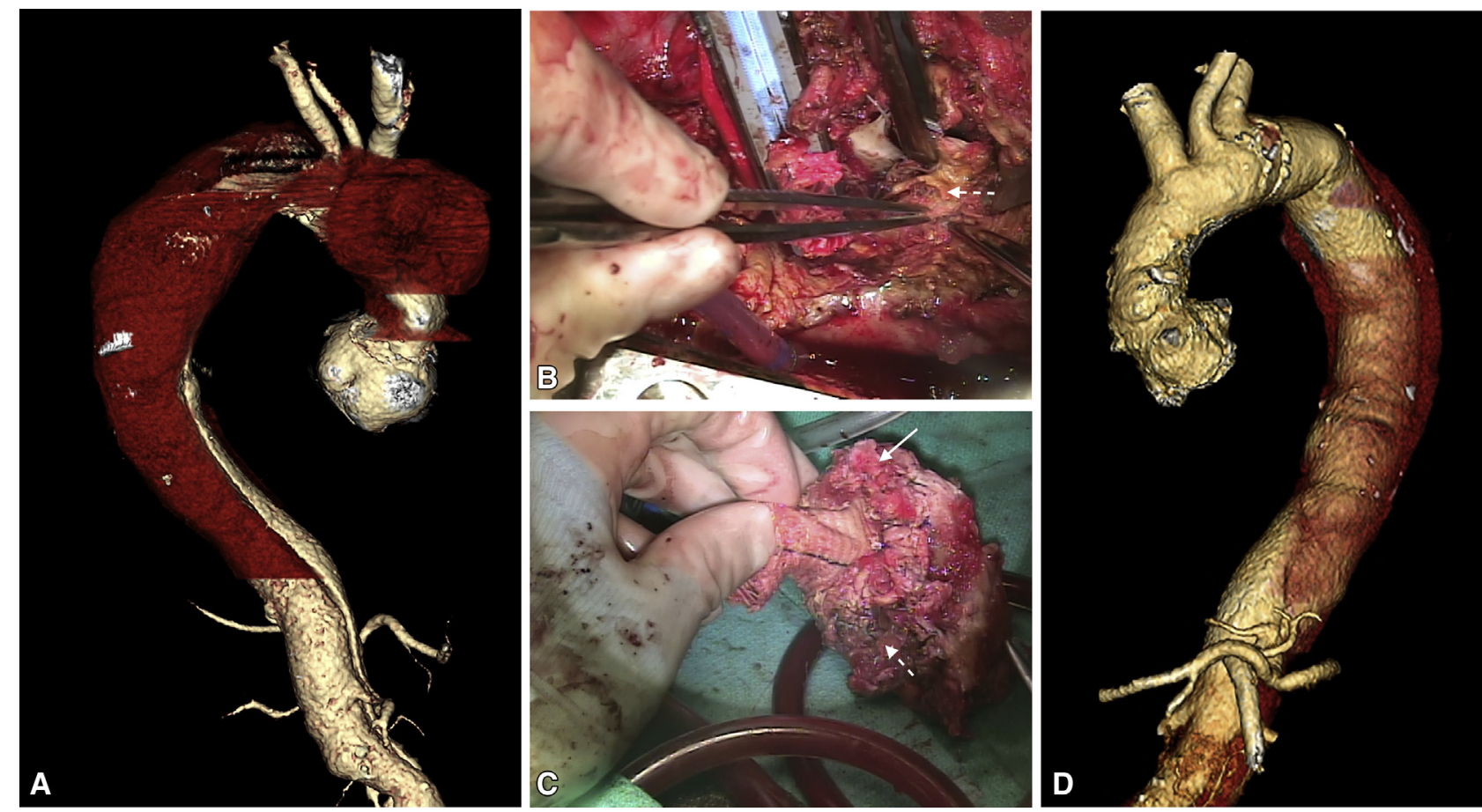

FIGURE 2. Pseudoaneurysm, extensive adhesions, inflammations, and tissue necrosis resulting from the use of biologic glue 10 years after repair of acute type A aortic dissection. A, Three-dimensional reconstruction of computed tomographic angiogram showing the ascending pseudoaneurysm. B, Extensive adhesions, necrosis (dashed arrow), and inflammation at the proximal anastomosis. C, Resected distal anastomosis showing extensive adhesions and inflammations resulting from polytetrafluoroethylene felt and biologic glue (solid arrow pointing at polytetrafluoroethylene felt; dashed arrow pointing at tissue necrosis). D, Three-dimensional reconstruction of computed tomographic angiogram showing 2-stage repair. Stage 1: redo total root, ascending aorta, and hemiarch replacement. Stage 2: reverse hemiarch and descending thoracic aorta replacement.

patients $(21 \%)$ had ATAAD; 1 patient with ATAAD had an anastomotic pseudoaneurysm develop 3 years postoperatively. Personally, in the past 5 years, I have reoperated on a handful of patients with proximal aortic anastomotic pseudoaneurysms resulting from biologic glue used in the initial repair of ATAAD at other hospitals. Every patient had severe inflammation and tissue necrosis related to BioGlue, and extensive adhesions as a result of polytetrafluoroethylene felt ${ }^{2}$ (Figures 1 and 2).

Since the introduction of biologic glue (initially gelatin-resorcinol-formaldehyde "French" glue) in the early 1990s, some surgeons have considered biologic glue as a life-saving adjunct, despite its toxicity-the more, the better. I am concerned that if we continue to believe that the use of biologic glue is necessary and safe for ATAAD repair, surgeons will continue to use it extensively despite its toxicity, cost, and potential long-term side effects. At the University of Michigan, we stopped using biologic glue in 2004, as have other major thoracic aortic surgical centers, such as Stanford University (Dr Craig Miller stopped using polytetrafluoroethylene felt reinforcement in 1996) and the University of Pennsylvania (personal communications).
In summary, if ATAAD can be repaired without any surgical adjuncts, such as biologic glue or polytetrafluoroethylene felt, these adjuncts should be avoided.

Bo Yang, MD, PhD

Department of Cardiac Surgery Michigan Medicine

Ann Arbor, Mich

\section{References}

1. Lee MK, Choi JB. Does the use of Teflon felt and BioGlue in the repair of acute type A aortic dissection significantly impact the surgical outcome? J Thorac Cardiovasc Surg. 2019;157:e118-9.

2. Yang B, Malik A, Waidley V, Kleeman KC, Wu X, Norton EL, et al. Shortterm outcomes of a simple and effective approach to aortic root and arch repair in acute type A aortic dissection. J Thorac Cardiovasc Surg. 2018; 155:1360-70.e1.

3. Yang B, Norton EL, Hobbs R, Farhat L, Wu X, Hornsby WE, et al. Short- and long-term outcomes of aortic root repair and replacement in patients undergoing acute type A aortic dissection repair: 20-year experience. J Thorac Cardiovasc Surg. December 21, 2018 [Epub ahead of print]

4. Andersen ND, Ganapathi AM, Hanna JM, Williams JB, Gaca JG, Hughes GC Outcomes of acute type a dissection repair before and after implementation of a multidisciplinary thoracic aortic surgery program. J Am Coll Cardiol. 2014;63: 1796-803.

5. Miller DC. Another meiosis in the specialty of cardiovascular and thoracic surgery: birth of the purebred "thoracic aortic surgeon"? J Am Coll Cardiol. 2014;63:1804-6.

6. Ma WG, Ziganshin BA, Guo CF, Zafar MA, Sieller RS, Tranquilli M, et al. Does BioGlue contribute to anastomotic pseudoaneurysm after thoracic aortic surgery? J Thorac Dis. 2017;9:2491-7. 
7. Kobayashi T, Kurazumi H, Sato M, Gohra H. Pseudoaneurysm rupture after acute type A dissection repair: possible reaction to BioGlue. Interact Cardiovasc Thorac Surg. 2018;26:331-2.

8. Tanaka H, Ikeno Y, Abe N, Takahashi H, Inoue T, Okita Y. Outcomes of valvesparing root replacement in acute type A aortic dissection. Eur J Cardiothorac Surg. 2018:53:1021-6.
9. Kitamura T, Torii S, Kobayashi K, Tanaka Y, Sasahara A, Araki H, et al. Repeat surgical intervention after aortic repair for acute Stanford type A dissection. Gen Thorac Cardiovasc Surg. 2018;66:692-9.

https://doi.org/10.1016/j.jtcvs.2018.11.073 